\title{
Corrosion Behaviour of T92 Steel in NaCl Solution
}

Yi Long ${ }^{1,2}$, Chao Feng ${ }^{1,2}$, Bicao Peng ${ }^{1,2}$, Yi Xie ${ }^{1,2}$, Jun Wang ${ }^{1,2}$, Minghua Zhang ${ }^{3}$, Yuanhui Wu ${ }^{4}$, Tangqing $\mathrm{Wu}^{3, *}$, Fucheng Yin $^{3}$

${ }^{1}$ Electric Power Research Institute, State Grid Hunan Electric Power Company, Changsha 410007, China;

${ }^{2}$ Hunan Xiangdian Boiler \& Pressure Vessel Inspection Center co., LTD, Changsha 410001, China;

${ }^{3}$ Key Laboratory of Materials Design and Preparation Technology of Hunan Province, Xiangtan University, Xiangtan 411105, China

${ }^{4}$ School of Chemistry and Chemical Engineering, Zunyi Normal College, Zunyi 563002, China

*E-mail: tqwu10s@alum.imr.ac.cn

doi: $10.20964 / 2017.06 .13$

Received: 23 January 2017 / Accepted: 18 March 2017 / Published: 12 May 2017

In the paper, the effects of $\mathrm{NaCl}$ on the corrosion behaviour of $\mathrm{T} 92$ steel at room temperature were studied by neutral salt spray test, electrochemical technology and scanning electron microscope. The results show that the corrosion rate of $\mathrm{T} 92$ steel continuously increase with the $\mathrm{NaCl}$ concentration during the neutral salt spray tests. $\mathrm{NaCl}$ promotes the anodic process rather than the cathodic process of the $\mathrm{T} 92$ steel in solution. In $\mathrm{NaCl}$ solutions with low concentrations, T92 steel undergoes uniform corrosion, wheres its corrosion behaviour will develop into pitting as the concentration of $\mathrm{NaCl}$ increase. The formation and development mechanism for the corrosion pitting are also discussed in the paper.

Keywords: T92, salt spray test, electrochemical impedance spectroscopy (EIS), scanning electron microscope (SEM), pitting

\section{$\underline{\text { FULL TEXT }}$}

(C) 2017 The Authors. Published by ESG (www.electrochemsci.org). This article is an open access article distributed under the terms and conditions of the Creative Commons Attribution license (http://creativecommons.org/licenses/by/4.0/). 